\title{
Pattern of cigarette and waterpipe smoking in the adult population of Jordan
}

M. Jaghbir,' S. Shreif' and M. Ahram²

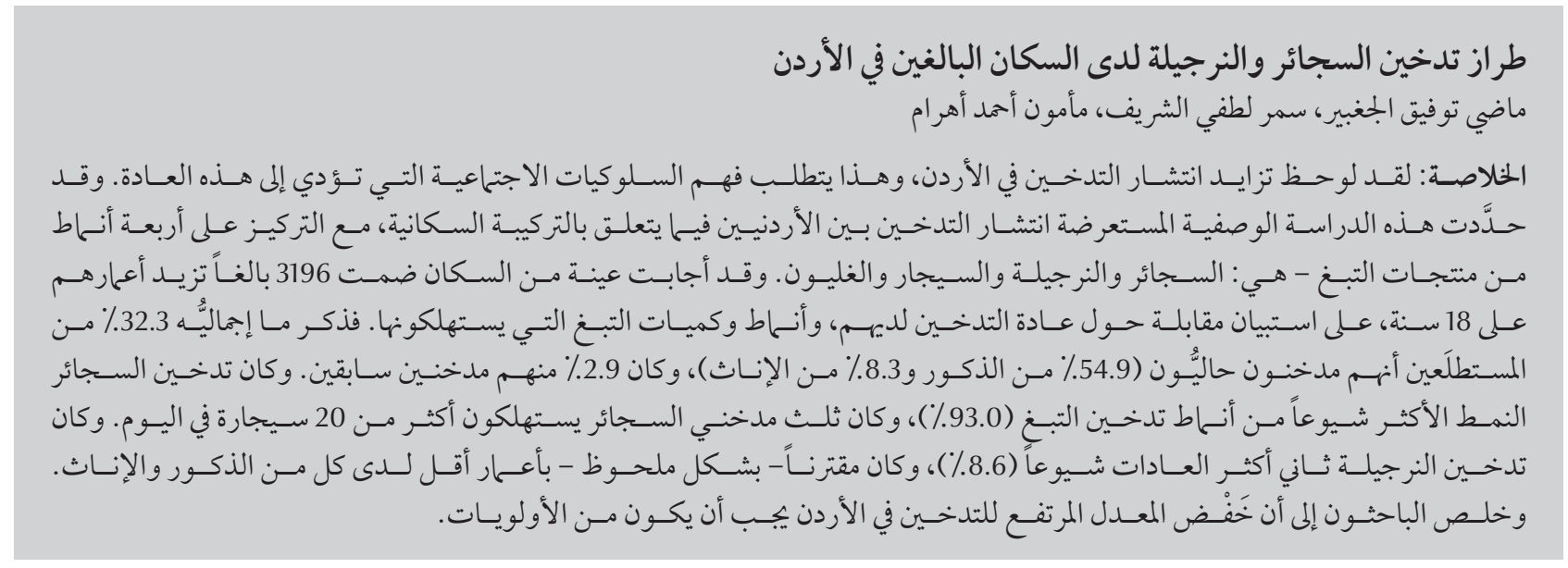

ABSTRACT An increasing prevalence of smoking in Jordan has been noted and this necessitates understanding the social behaviours that have lead to this habit. This cross-sectional, descriptive study determined the prevalence of smoking among Jordanians in relation to demographics with a focus on 4 types of tobacco products-cigarettes, waterpipes, cigars and pipes. A population sample of 3196 adults aged 18+ years answered an interview questionnaire about their smoking habit and types and amounts of tobacco consumed. Overall $32.3 \%$ of the respondents reported being current smokers (54.9\% of males and $8.3 \%$ of females) and $2.9 \%$ were ex-smokers. Cigarette smoking was the most frequent type of tobacco smoking (93.0\%) and one-third of cigarette smokers consumed more than 20 cigarettes per day. Waterpipe smoking was the second most common habit $(8.6 \%)$ and was significantly associated with lower age in both males and females. Reducing the high rate of smoking in Jordan must be a priority.

\section{Caractéristiques de la consommation de cigarettes et du narguilé dans la population adulte de Jordanie}

RÉSUMÉ Une prévalence accrue de la consommation de tabac a été observée en Jordanie et cette augmentation nécessite une compréhension des comportements sociaux qui conduisent à cette habitude. La présente étude transversale descriptive a déterminé la prévalence de la consommation de tabac chez les Jordaniens axée sur quatre types de produit -les cigarettes, les narguilés, les cigares et les pipes, en tenant compte des données démographiques. Un échantillon de population de 3196 adultes âgés de 18 ans et plus a répondu à un questionnaire administré pendant un entretien sur les habitudes de consommation de tabac et les types et quantités de tabac consommés. Dans l'ensemble, 32,3\% des répondants ont déclaré être des fumeurs actifs (54,9\% d'hommes et 8,3\% de femmes) et 2,9\% étaient d'anciens consommateurs de tabac. Fumer des cigarettes était la forme de consommation de tabac la plus fréquente $(93,0 \%)$ et un tiers d'entre eux fumaient plus de 20 cigarettes par jour. Fumer le narguilé arrivait en deuxième position dans les habitudes de consommation (8,6 \%) et était significativement associé à un âge plus jeune chez les hommes comme chez les femmes. Réduire le fort taux de consommation de tabac en Jordanie doit être une priorité. 


\section{Introduction}

The World Health Organization (WHO) has described tobacco smoking as an epidemic (1). Strong evidence links tobacco smoking to mortality and numerous diseases, primarily cardiovascular diseases and cancer $(2,3)$. The estimated number of smoking-related annual deaths from smoking-attributable diseases are expected to increase to 10 million within the next 30 years or so, of which $70 \%$ will occur in developing countries (4). In Jordan, an Eastern Mediterranean Region (EMR) country, cardiovascular disease is the leading cause of mortality (36.1\%), followed by cancer (15.6\%) (5). In fact, cancer cases in Jordan are steadily increasing. For example, according to the Jordan Cancer Registry, there has been a $4 \%$ increase in cancer cases between 2008 and 2009 (6). Lung cancer ranked second among males (11.2\%), closely following colorectal cancer (12.7\%) (6). It is well accepted that at least one-third of all the new cases of cancer every year can be prevented and that tobacco is one of the most preventable causes of cancer. Hence, tobacco control should be established as the top priority in public health programmes for disease prevention, including cancer.

Rates of smoking and tobacco consumption are variable across the EMR, with a high smoking prevalence in some countries, such as Lebanon, Jordan, Egypt, Tunisia and the Syrian Arab Republic (7). A review of 36 studies related to the prevalence of smoking in Saudi Arabia has indicated rates of up to $52.3 \%$ (8). Among EMR countries, Jordan had the highest age-standardized rate of smoking (36.5\%) followed by Tunisia (25.7\%) (9). Significantly, the rate of smoking has been on the increase in the EMR countries $(9,10)$. The same trend is expected to be occurring in Jordan, which suggests that the number of Jordanians who will die or be disabled as a result of tobacco-related diseases will increase. Due to the relatively low age of the population, the rate of smokingrelated disease is expected to increase. In order to learn more about public smoking habits including the rates and types of products smoked, a questionnaire was conducted as part of a national survey of knowledge, attitudes and practices (KAP) towards cancer prevention and care in Jordan that included questions about smoking habits. Overall, the focus of the study was to help identify the current smoking practices among the population of Jordan in an effort to better control this life-threatening habit. This was the first study of its kind at the national level in Jordan.

\section{Methods}

\section{Study design}

This was a quantitative, cross-sectional, descriptive survey. Data collection spanned 2 months from 24 January to 19 March 2011. The survey consisted of 10 sections starting with a section about demographic characteristics. One section enquired about the lifestyle of participants and included questions about smoking habits. The results of this part of the survey form the focus of this paper.

\section{Participants}

The KAP survey sample was based on the 2004 Jordan Population and Housing Census as the sampling frame. The sampling frame was stratified by governorate, major cities (each city with a population of more than 100000 was considered a stratum, i.e. 6 cities) and other urban and other rural areas. A 3-stage sampling procedure was employed. First, blocks were selected systematically as primary sampling units (PSUs) with a probability proportional to the size of the PSU. In the second stage, a fixed number of 15 households were selected as final sampling units in each PSU, resulting in a sample size of about 4500 households. In the third stage, random selection of individual interviewees from each household was carried out using Kish tables (11). The final sample size in this survey was 3196 participants (a response rate of 93\%). Overall, the characteristics of survey participants correlated well with national estimates, as published earlier (12).

\section{Instrument}

A structured questionnaire was designed by a national advisory committee that consisted of research experts from different research, clinical and academic institutions in Jordan. The design of the survey was based on international references/tools that were used as a guide to the development of the questionnaire and to ensure appropriate themes and adaptation to the local context. Face-to-face interviews were conducted in interviewees' households and took an average of 30 minutes to complete. Verbal informed consent was obtained; agreement to host interviews in the participants' house is a culturally appropriate method to obtain consent in Jordan.

A pilot study was conducted to test the survey tool, sampling technique, survey methods and interviewers' level of work. The pilot study spanned a day and was carried out in one area in the capital city, Amman. The pilot sample consisted of 56 randomly selected subjects. Following the pilot, a 2-day review session was conducted and resulted in implementation of minor modifications.

\section{Measures}

Respondents were first asked if they considered themselves as non-smokers, current smokers or ex-smokers. Those who described themselves as current smokers were asked about the types of tobacco they used and 4 options were provided: cigarettes, cigars, pipes and waterpipes (nargile). In addition, respondents were asked about the amount of tobacco consumed (i.e. 
number of times each type of tobacco product was smoked daily).

\section{Data collection}

Data collection was carried out in the 3 regions of Jordan (North, Middle and South). The face-to-face interviews were conducted by 18 trained teams. Each team consisted of 3 data collectors, 1 controller, 1 field supervisor and 1 driver. The controllers and supervisors conducted spot checks by randomly visiting some sampled households. In order to facilitate data collection, each interviewing team was assigned a number of blocks in the sample area. Interviewers made repeated attempts to obtain the responses of eligible respondents by calling back to interview respondents who were not home at the time of the first visit or by attempting to persuade respondents who were reluctant to be interviewed.

\section{Data processing and analysis}

Data entry using Oracle software started 1 week after the initiation of data collection. After editing and cleaning, the data were exported to SPSS, version 17.0. SPSS was used to run univariate and bivariate analyses to describe all the survey variables. As most of the variables in the study were measured on a nominal and/or ordinal level, descriptive statistics were used to describe the basic features of the data. The chi-squared test was used to correlate demographic data with smoking habits.

\section{Results}

\section{Demographic characteristics}

A total of 3196 respondents participated in the survey. Their demographic characteristics are summarized in Table 1. There was an approximately equal distribution of males and females. The respondents' mean age was 39 years, with about $78 \%$ of the participants being between 18 and 49 years of age. The highest percentage of participants had attained preparatory to high-school education (51.3\%), with the remainder having a diploma degree and above (29.5\%) or elementary education and below (19.2\%). Approximately half of respondents had a monthly household income below 300 Jordanian dinar (JD) (US \$430). Individuals with the medium income (300-599 JD) represented $38.7 \%$ and those with high income (above 600 JD) represented $14.2 \%$. The majority of respondents were married (73.1\%), and most of the rest were single (19.9\%); the "other" category (7.0\%) included those who were widowed, divorced or separated.

\section{Pattern of smoking habits}

When participants were asked about their smoking habits, $64.8 \%$ of them reported that they had never smoked, whereas $32.3 \%$ were current smokers and $2.9 \%$ were ex-smokers (Table 1). The prevalence of current smoking varied greatly according to sex, whereby $54.9 \%$ of male respondents reported being current smokers compared with only $8.3 \%$ of females ( $P$ $<0.001)$. A significant difference in smoking habits was also noted with age, with the highest prevalence being in the $40-49$ years age group (40.0\%) and the lowest among those aged $60+$ years $(16.3 \%)(P<0.001)$. Intermediate educational status had a significant association with smoking habits, with more than one-third of them (36.9\%) being current smokers versus approximately $27 \%$ of the groups of lower and higher educational status $(P<0.001)$. No significant relationship was found between smoking habits and income $(P=0.379)$. A significant effect of marital status on smoking habits was found; those who were divorced,

\begin{tabular}{|c|c|c|}
\hline Characteristic & No. & $\%$ \\
\hline \multicolumn{3}{|l|}{ Sex } \\
\hline Male & 1647 & 51.5 \\
\hline Female & 1549 & 49.5 \\
\hline \multicolumn{3}{|l|}{ Age (years) } \\
\hline $18-29$ & 964 & 30.1 \\
\hline 30-39 & 915 & 28.6 \\
\hline $40-49$ & 627 & 19.6 \\
\hline $50-59$ & 271 & 8.5 \\
\hline $60+$ & 419 & 13.1 \\
\hline \multicolumn{3}{|l|}{ Education } \\
\hline Elementary or less & 614 & 19.2 \\
\hline Preparatory to high school & 1638 & 51.3 \\
\hline Diploma and above & 944 & 29.5 \\
\hline \multicolumn{3}{|l|}{ Monthly income $(J D)^{a}$} \\
\hline$<300$ & 1495 & 47.1 \\
\hline $300-599$ & 1227 & 38.7 \\
\hline $600+$ & 452 & 14.2 \\
\hline \multicolumn{3}{|l|}{ Marital status $^{b}$} \\
\hline Single & 636 & 19.9 \\
\hline Married & 2338 & 73.1 \\
\hline Other ${ }^{\mathrm{a}}$ & 222 & 7.0 \\
\hline
\end{tabular}

${ }^{a} 22$ respondents refused to declare their income; ${ }^{b}$ This category included divorced, widowed and separated. $J D=$ Jordanian dinar. 
widowed or separated were more likely to be non- or ex-smokers than were single and married individuals $(P<0.001)$. The latter 2 groups, single and married respondents, appeared to have similar smoking habits; $61.9 \%$ versus $63.9 \%$ respectively were nonsmokers, while $36.5 \%$ versus $33.0 \%$ respectively were current smokers.

\section{Pattern of smoking according to sex}

When analysing the data in more detail to look at differences in smoking habits between males and females some interesting associations were noted (Table 2). Whereas the percentage of males smoking was low only among those $60+$ years old $(P<0.001)$, the lowest percentage of female smokers was among the youngest (18-29 years) and oldest $(60+$ years $)$ age groups $(P<0.001)$. Similarly, the prevalence of smoking by single and married male smokers was higher than among those who were divorced, widowed or separated $(P<0.001)$. On the other hand, more married females smoked than the single or other categories $(P=0.01)$. When looking at the aforementioned overall smoking habits, there was no association between smoking and income among females. However, males with lower income were more likely to be smokers than those with higher income $(P<0.001)$. Income did not show any significant effect on the prevalence of smoking among females $(P=0.894)$. It is noteworthy that more males with intermediate education smoked than those with lower and higher educational status $(P<0.001)$. The prevalence of smoking was significantly different among females according to level of education $(P=0.046)$.

\section{Type of smoking}

Current smokers $(n=1032)$ were asked about the type of tobacco products they smoked daily (Table $3)$. The majority indicated that they smoked cigarettes (93.0\%). There

\begin{tabular}{|c|c|c|c|c|c|c|}
\hline \multirow{2}{*}{$\begin{array}{l}\text { How would you describe your smoking } \\
\text { habits of any tobacco products? }\end{array}$} & \multicolumn{2}{|c|}{ Non-smoker } & \multicolumn{2}{|c|}{ Current smoker } & \multicolumn{2}{|c|}{ Ex-smoker } \\
\hline & No. & $\%$ & No. & $\%$ & No. & $\%$ \\
\hline Total & 2072 & 64.8 & 1032 & 32.3 & 93 & 2.9 \\
\hline \multicolumn{7}{|l|}{ Sex } \\
\hline Male & 669 & 40.6 & 904 & 54.9 & 75 & 4.6 \\
\hline \multirow[t]{2}{*}{ Female } & 1403 & 90.6 & 128 & 8.3 & 18 & 1.2 \\
\hline & \multicolumn{6}{|c|}{$\chi^{2}=876.2 ; P<0.001$} \\
\hline \multicolumn{7}{|l|}{ Age (years) } \\
\hline 18-29 & 652 & 67.7 & 295 & 30.6 & 16 & 1.7 \\
\hline $30-39$ & 555 & 60.6 & 336 & 36.7 & 25 & 2.7 \\
\hline $40-49$ & 362 & 57.7 & 251 & 40.0 & 14 & 2.2 \\
\hline $50-59$ & 179 & 66.3 & 82 & 30.4 & 9 & 3.3 \\
\hline \multirow[t]{2}{*}{$60+$} & 322 & 77.0 & 68 & 16.3 & 28 & 6.7 \\
\hline & \multicolumn{6}{|c|}{$\chi^{2}=97.1 ; P<0.001$} \\
\hline \multicolumn{7}{|l|}{ Education } \\
\hline Elementary or less & 411 & 66.8 & 167 & 27.2 & 37 & 6.0 \\
\hline Preparatory to high school & 996 & 60.8 & 604 & 36.9 & 38 & 2.3 \\
\hline \multirow[t]{2}{*}{ Diploma and above } & 664 & 70.3 & 262 & 27.8 & 18 & 1.9 \\
\hline & \multicolumn{6}{|c|}{$\chi^{2}=56.2 ; P<0.001$} \\
\hline \multicolumn{7}{|l|}{ Monthly income $(J D)^{a}$} \\
\hline$<300$ & 946 & 63.3 & 502 & 33.6 & 47 & 3.1 \\
\hline $300-599$ & 804 & 65.5 & 390 & 31.8 & 33 & 2.7 \\
\hline \multirow[t]{2}{*}{$600+$} & 307 & 67.9 & 135 & 29.9 & 10 & 2.2 \\
\hline & \multicolumn{6}{|c|}{$\chi^{2}=4.2 ; P=0.379$} \\
\hline \multicolumn{7}{|l|}{ Marital status } \\
\hline Single & 394 & 61.9 & 232 & 36.5 & 10 & 1.6 \\
\hline Married & 1495 & 63.9 & 772 & 33.0 & 71 & 3.0 \\
\hline \multirow[t]{2}{*}{ Other } & 182 & 82.0 & 28 & 12.6 & 12 & 5.4 \\
\hline & \multicolumn{6}{|c|}{$\chi^{2}=50.4 ; P<0.001$} \\
\hline
\end{tabular}

${ }^{a} 22$ respondents refused to declare their income. 


\begin{tabular}{|c|c|c|c|c|c|c|c|c|c|c|c|c|}
\hline \multirow{3}{*}{$\begin{array}{l}\text { How would you describe your } \\
\text { smoking habits of any tobacco } \\
\text { products? }\end{array}$} & \multicolumn{6}{|c|}{ Males } & \multicolumn{6}{|c|}{ Females } \\
\hline & \multicolumn{2}{|c|}{ Non-smoker } & \multicolumn{2}{|c|}{$\begin{array}{l}\text { Current } \\
\text { smoker }\end{array}$} & \multicolumn{2}{|c|}{ Ex-smoker } & \multicolumn{2}{|c|}{ Non-smoker } & \multicolumn{2}{|c|}{$\begin{array}{l}\text { Current } \\
\text { smoker }\end{array}$} & \multicolumn{2}{|c|}{ Ex-smoker } \\
\hline & No. & $\%$ & No. & $\%$ & No. & $\%$ & No. & $\%$ & No. & $\%$ & No. & $\%$ \\
\hline \multicolumn{13}{|l|}{ Age (years) } \\
\hline $18-29$ & 199 & 40.8 & 276 & 56.6 & 13 & 2.7 & 453 & 95.4 & 19 & 4.0 & 3 & 0.6 \\
\hline $30-39$ & 163 & 34.1 & 293 & 61.3 & 22 & 4.6 & 392 & 89.7 & 43 & 9.8 & 2 & 0.5 \\
\hline $40-49$ & 123 & 35.4 & 213 & 61.4 & 11 & 3.2 & 239 & 85.7 & 37 & 13.3 & 3 & 1.1 \\
\hline $50-59$ & 36 & 34.0 & 66 & 62.3 & 4 & 3.8 & 143 & 86.7 & 17 & 10.3 & 5 & 3.0 \\
\hline \multirow[t]{2}{*}{$60+$} & 147 & 65.0 & 56 & 24.8 & 23 & 10.2 & 175 & 91.1 & 12 & 6.2 & 5 & 2.6 \\
\hline & \multicolumn{6}{|c|}{$\chi^{2}=108.1 ; P<0.001$} & \multicolumn{6}{|c|}{$\chi^{2}=35.65 ; P<0.001$} \\
\hline \multicolumn{13}{|l|}{ Education } \\
\hline Elementary or less & 93 & 36.2 & 137 & 53.3 & 27 & 10.5 & 318 & 88.6 & 30 & 8.4 & 10 & 2.8 \\
\hline Preparatory to high school & 317 & 35.5 & 544 & 60.9 & 32 & 3.6 & 680 & 91.2 & 60 & 8.0 & 6 & 0.8 \\
\hline \multirow[t]{2}{*}{ Diploma and above } & 259 & 52.0 & 223 & 44.8 & 16 & 3.2 & 405 & 90.6 & 39 & 8.7 & 3 & 0.7 \\
\hline & \multicolumn{6}{|c|}{$\chi^{2}=62.06 ; P<0.001$} & \multicolumn{6}{|c|}{$\chi^{2}=9.69 ; P=0.046$} \\
\hline \multicolumn{13}{|l|}{ Monthly income $(J D)^{a}$} \\
\hline$<300$ & 255 & 34.7 & 442 & 60.1 & 38 & 5.2 & 691 & 90.8 & 60 & 7.9 & 10 & 1.3 \\
\hline $300-599$ & 288 & 44.0 & 338 & 51.7 & 28 & 4.3 & 516 & 89.9 & 52 & 9.1 & 6 & 1.0 \\
\hline \multirow[t]{2}{*}{$600+$} & 123 & 49.2 & 120 & 48.0 & 7 & 2.8 & 185 & 91.1 & 15 & 7.4 & 3 & 1.5 \\
\hline & \multicolumn{6}{|c|}{$\chi^{2}=22.26 ; P<0.001$} & \multicolumn{6}{|c|}{$\chi^{2}=1.10 ; P=0.894$} \\
\hline \multicolumn{13}{|l|}{ Marital status } \\
\hline Single & 190 & 44.8 & 224 & 52.8 & 10 & 2.4 & 204 & 44.8 & 8 & 3.8 & 0 & 0.0 \\
\hline Married & 457 & 38.6 & 669 & 56.5 & 58 & 4.9 & 457 & 38.6 & 669 & 56.5 & 58 & 4.9 \\
\hline \multirow[t]{2}{*}{ Other } & 22 & 56.4 & 10 & 25.6 & 7 & 17.9 & 160 & 87.9 & 17 & 9.3 & 5 & 2.7 \\
\hline & \multicolumn{6}{|c|}{$\chi^{2}=32.56 ; P<0.001$} & \multicolumn{6}{|c|}{$\chi^{2}=16.02 ; P=0.003$} \\
\hline
\end{tabular}

${ }^{a} 22$ respondents refused to declare their income.

was a significant difference in the prevalence of cigarette smoking by sex, in which $93.7 \%$ of males smoked cigarettes in comparison with $88.3 \%$ of females $(P=0.025)$. A significant difference was also found across the different age groups $(P=0.042)$. The rate of cigarette smoking was highest among age groups $40-49$ years (96.4\%), 50-59 years (95.2\%) and $60+$ years $(95.6 \%)$, and lowest among the age groups $18-29$ years (90.5\%) and $30-39$ years $(91.4 \%)$. On the other hand, income, level of education and marital status were not associated with cigarette smoking $(P=0.361, P$ $=0.167$ and $P=0.267$ respectively). Approximately half of smokers consumed 11-20 cigarettes a day and almost one-third consumed more than 20 cigarettes a day (Table 4).
Smoking waterpipes daily rated second among the 4 types of tobacco products; 89 respondents $(8.6 \%)$ indicated that they smoked this type of tobacco product. Waterpipe smoking had a significant negative association with age, with the highest percentage (13.3\%) among the age group 18-29 years and the lowest among those aged $60+$ years $(1.5 \%)(P<0.001)$ (Table 5). No significant difference, however, was found between waterpipe smoking and sex, level of education, income or marital status $(P=0.072, P=0.254$, $P=0.514$ and $P=0.065$ respectively). Smoking cigars and pipes were the least common habits, with a rate of $0.5 \%(n=5)$ and $0.2 \%(n=2)$ respectively. Only 23 (2.4\%) respondents indicated that they smoked both cigarettes and waterpipes daily.

\section{Type of smoking habit according to sex}

We examined the types of smoking (cigarettes and waterpipes) according to sex (Table 6). Whereas there was no significant difference among females in the percentage smoking cigarettes by age $(P=0.062)$, the percentage of males smoking cigarettes tended to be lowest in the youngest age group (18-29 years) and peaked at the middle age group (40-49 years) $(P=0.024)$. In contrast, the prevalence of waterpipe smoking was significantly higher at lower ages among both males and females $(P=$ 0.014 and 0.004 respectively). There was a significant difference in waterpipe smoking by females according to marital status, whereby single females were more likely to smoke 


\begin{tabular}{lccc}
\hline \multicolumn{4}{l}{ Table 4 Number of cigarettes consumed daily by cigarette smokers $(\boldsymbol{n}=\mathbf{9 6 0})$} \\
\hline No. of cigarettes & No. & $\%$ & Cumulative \% \\
$1-10$ & 165 & 17.2 & 17.2 \\
$11-20$ & 461 & 48.0 & 65.2 \\
$21-30$ & 114 & 11.9 & 77.1 \\
$31-40$ & 176 & 18.3 & 95.4 \\
$41-50$ & 8 & 0.8 & 96.2 \\
$51-100$ & 36 & 3.8 & 100.0 \\
\hline
\end{tabular}

this type of tobacco product than married women or other categories $(P=0.031)$, a trend that was not observed among males $(P=0.175)$. However, we need to be cautious in interpreting these data due to the low number of females admitting to smoking waterpipes. No significant differences were noted in smoking either cigarettes or waterpipes between males and females according to education or income.

\section{Discussion}

This study offers 3 important findings. First of all, the overall prevalence of current smoking in Jordan was $32.3 \%$ and this reached $54.9 \%$ among males above 18 years old. These figures are higher than previous reports from the country as will be discussed below. Second, a major concern was the degree of consumption as almost $80 \%$ of the smokers consumed more than 10 cigarettes a day. The third important finding is that the rate of waterpipe smoking was the highest among the young females and males.

\begin{tabular}{|c|c|c|c|c|c|c|c|c|}
\hline \multirow{2}{*}{$\begin{array}{l}\text { What kind of tobacco do you } \\
\text { smoke? }\end{array}$} & \multicolumn{2}{|c|}{ Cigarettes } & \multicolumn{2}{|c|}{ Waterpipes } & \multicolumn{2}{|c|}{ Cigars } & \multicolumn{2}{|c|}{ Pipes } \\
\hline & No. & $\%$ & No. & $\%$ & No. & $\%$ & No. & $\%$ \\
\hline Total & 960 & 93.0 & 89 & 8.6 & 5 & 0.5 & 2 & 0.2 \\
\hline \multicolumn{9}{|l|}{ Sex } \\
\hline Male & 846 & 93.7 & 73 & 8.1 & 3 & 0.3 & 2 & 0.2 \\
\hline \multirow[t]{2}{*}{ Female } & 113 & 88.3 & 16 & 12.5 & 2 & 0.6 & 0 & 0.0 \\
\hline & \multicolumn{2}{|c|}{$\chi^{2}=5.0 ; P=0.025$} & \multicolumn{2}{|c|}{$\chi^{2}=2.8 ; P=0.072$} & \multicolumn{2}{|c|}{$\chi^{2}=3.5 ; P=0.120$} & \multicolumn{2}{|c|}{$\chi^{2}=0.28 ; P=0.767$} \\
\hline \multicolumn{9}{|l|}{ Age (years) } \\
\hline 18-29 & 267 & 90.5 & 39 & 13.2 & 0 & 0 & 0 & 0.0 \\
\hline 30-39 & 307 & 91.4 & 33 & 9.8 & 2 & 0.6 & 0 & 0.0 \\
\hline $40-49$ & 242 & 96.4 & 14 & 5.6 & 1 & 0.4 & 0 & 0.0 \\
\hline $50-59$ & 79 & 95.2 & 3 & 3.6 & 1 & 1.2 & 1 & 1.2 \\
\hline \multirow[t]{2}{*}{$60+$} & 65 & 95.6 & 1 & 1.5 & 1 & 1.5 & 1 & 1.5 \\
\hline & \multicolumn{2}{|c|}{$\chi^{2}=9.9 ; P=0.04$} & \multicolumn{2}{|c|}{$\chi^{2}=18.2 ; P=0.001$} & \multicolumn{2}{|c|}{$\chi^{2}=3.8 ; P=0.430$} & \multicolumn{2}{|c|}{$\chi^{2}=11.8 ; P=0.02$} \\
\hline \multicolumn{9}{|l|}{ Education } \\
\hline Elementary or less & 155 & 92.8 & 13 & 7.8 & 0 & 0.0 & 1 & 0.6 \\
\hline Preparatory to high school & 568 & 94.0 & 47 & 7.8 & 3 & 0.5 & 1 & 0.2 \\
\hline \multirow[t]{2}{*}{ Diploma and above } & 237 & 90.5 & 29 & 11.1 & 2 & 0.8 & 0 & 0.0 \\
\hline & \multicolumn{2}{|c|}{$\chi^{2}=3.6 ; P=0.17$} & \multicolumn{2}{|c|}{$\chi^{2}=2.7 ; P=0.25$} & \multicolumn{2}{|c|}{$\chi^{2}=1.2 ; P=0.53$} & \multicolumn{2}{|c|}{$\chi^{2}=2.0 ; P=0.38$} \\
\hline \multicolumn{9}{|l|}{ Monthly income $(J D)^{b}$} \\
\hline$<300$ & 472 & 94.0 & 40 & 8.0 & 1 & 0.2 & 1 & 0.2 \\
\hline $300-599$ & 359 & 92.1 & 34 & 8.7 & 2 & 0.5 & 1 & 0.3 \\
\hline \multirow[t]{2}{*}{$600+$} & 123 & 91.1 & 15 & 11.1 & 1 & 0.7 & 0 & 0.0 \\
\hline & \multicolumn{2}{|c|}{$\chi^{2}=2.0 ; P=0.361$} & \multicolumn{2}{|c|}{$\chi^{2}=1.3 ; P=0.51$} & \multicolumn{2}{|c|}{$\chi^{2}=1.1 ; P=0.592$} & \multicolumn{2}{|c|}{$\chi^{2}=0.34 ; P=0.84$} \\
\hline \multicolumn{9}{|l|}{ Marital status } \\
\hline Single & 213 & 91.8 & 27 & 11.6 & 0 & 0.0 & 0 & 0.0 \\
\hline Married & 719 & 93.1 & 63 & 8.2 & 5 & 0.6 & 2 & 0.3 \\
\hline Other & 28 & 100.0 & 0 & 0.0 & 0 & 0.0 & 0 & 0.0 \\
\hline & $\chi^{2}=2$. & $P=0.27$ & $\chi^{2}=1$. & $9 ; P=0.43$ & $\chi^{2}=0$ & $8 ; P=0.71$ & $\chi^{2}=5$. & $; P=0.07$ \\
\hline
\end{tabular}

${ }^{a} 23$ respondents indicated they smoked both cigarettes and waterpipes daily; ${ }^{b} 7$ respondents refused to declare their income. 


\begin{tabular}{|c|c|c|c|c|c|c|c|c|}
\hline \multirow{3}{*}{$\begin{array}{l}\text { What king of tobacco do you } \\
\text { smoke?a }\end{array}$} & \multicolumn{4}{|c|}{ Cigarettes } & \multicolumn{4}{|c|}{ Waterpipes } \\
\hline & \multicolumn{2}{|c|}{ Males } & \multicolumn{2}{|c|}{ Females } & \multicolumn{2}{|c|}{ Males } & \multicolumn{2}{|c|}{ Females } \\
\hline & No. & $\%$ & No. & $\%$ & No. & $\%$ & No. & $\%$ \\
\hline \multicolumn{9}{|l|}{ Age (years) } \\
\hline $18-29$ & 253 & 91.7 & 14 & 70.0 & 31 & 11.2 & 8 & 42.1 \\
\hline 30-39 & 268 & 91.8 & 39 & 90.7 & 29 & 9.9 & 4 & 9.3 \\
\hline $40-49$ & 209 & 98.1 & 33 & 89.2 & 11 & 5.2 & 3 & 8.1 \\
\hline $50-59$ & 63 & 95.5 & 16 & 94.1 & 2 & 3.0 & 1 & 5.9 \\
\hline \multirow[t]{2}{*}{$60+$} & 53 & 94.6 & 12 & 100.0 & 1 & 1.8 & 0 & 0.0 \\
\hline & \multicolumn{2}{|c|}{$\chi^{2}=11.22 ; P=0.024$} & \multicolumn{2}{|c|}{$\chi^{2}=8.95 ; P=0.062$} & \multicolumn{2}{|c|}{$\chi^{2}=12.5 ; P=0.01$} & \multicolumn{2}{|c|}{$\chi^{2}=15.5 ; P=0.004$} \\
\hline \multicolumn{9}{|l|}{ Education } \\
\hline Elementary or less & 126 & 92.0 & 29 & 96.7 & 12 & 8.8 & 1 & 3.3 \\
\hline Preparatory to high school & 517 & 95.0 & 51 & 85.0 & 39 & 7.2 & 9 & 15.0 \\
\hline \multirow[t]{2}{*}{ Diploma and above } & 203 & 91.4 & 34 & 87.2 & 23 & 10.3 & 7 & 17.9 \\
\hline & \multicolumn{2}{|c|}{$\chi^{2}=4.25 ; P=0.119$} & \multicolumn{2}{|c|}{$\chi^{2}=2.73 ; P=0.256$} & \multicolumn{2}{|c|}{$\chi^{2}=2.15 ; P=0.34$} & \multicolumn{2}{|c|}{$\chi^{2}=3.49 ; P=0.175$} \\
\hline \multicolumn{9}{|l|}{ Monthly income $(J D)^{b}$} \\
\hline$<300$ & 418 & 94.8 & 54 & 90.0 & 34 & 7.7 & 7 & 11.7 \\
\hline $300-599$ & 315 & 93.2 & 44 & 84.6 & 26 & 7.7 & 8 & 15.4 \\
\hline \multirow[t]{2}{*}{$600+$} & 109 & 90.8 & 15 & 93.8 & 13 & 10.8 & 1 & 6.7 \\
\hline & \multicolumn{2}{|c|}{$\chi^{2}=2.68 ; P=0.262$} & \multicolumn{2}{|c|}{$\chi^{2}=1.31 ; P=0.520$} & \multicolumn{2}{|c|}{$\chi^{2}=1.37 ; P=0.51$} & \multicolumn{2}{|c|}{$\chi^{2}=0.893 ; P=0.640$} \\
\hline \multicolumn{9}{|l|}{ Marital status } \\
\hline Single & 206 & 92.0 & 6 & 85.7 & 24 & 10.7 & 3 & 37.5 \\
\hline Married & 630 & 94.2 & 89 & 86.4 & 49 & 7.3 & 13 & 12.7 \\
\hline \multirow[t]{2}{*}{ Other } & 10 & 100.0 & 17 & 100.0 & 0 & 0.0 & 0 & 0.0 \\
\hline & \multicolumn{2}{|c|}{$\chi^{2}=2.06 ; P=0.357$} & \multicolumn{2}{|c|}{$\chi^{2}=2.63 ; P=0.268$} & \multicolumn{2}{|c|}{$\chi^{2}=3.49 ; P=0.175$} & \multicolumn{2}{|c|}{$\chi^{2}=6.96 ; P=0.031$} \\
\hline
\end{tabular}

${ }^{a} 23$ respondents indicated they smoked both cigarettes and waterpipes daily; ${ }^{b} 7$ respondents refused to declare their income.

The prevalence of smoking for both sexes was higher than previously reported figures. For example, in Jordan a survey 30 years ago reported that the rate of smoking was 29\% (7). This is in contrast to data published in the United States of America (USA), where smoking rates among adults halved from $42 \%$ to $20.8 \%$ between 1965 and 2011 , with $23.9 \%$ of men smoking compared with $18.1 \%$ of women (13). Rates of smoking are generally 5 times higher among men than women as described in our study as well as in other reports from the region (10). However, the gap between the sexes declines with younger ages (14). In developed countries, smoking rates for men have peaked and have begun to decline; on the other hand, the rate of smoking among women continues to increase (15). In our study, the prevalence of current smoking varied greatly between the sexes with the gap being highest at the youngest age group (14-fold) and lowest at the age groups $40-49$ years (4.6-fold) and $60+$ years (4-fold), in contrast to the aforementioned reports. The low prevalence of smoking among Jordanian women probably reflects cultural norms that dissuade women from starting to smoke. Therefore, awareness campaigns and stricter policies should be considered in Jordan to decrease the rate of smoking, as is the case in most developed countries. In addition, the creation of primary prevention programmes that promote non-smoking among Jordanian women might be useful in maintaining this low prevalence in the future.

The prevalence of current smoking among adults in the USA was $24.4 \%$ among those aged 18-24 years and
$24.1 \%$ at ages $25-44$ years, both of which were the highest rates across all age groups (13). The prevalence of smoking in our study varied significantly with age, reaching a peak at age 40-49 years. However, a major concern is the finding that both male and female youngsters were more likely to smoke waterpipes compared with older age groups. Such a trend has been consistently reported in Jordan and neighbouring countries, where both cigarette and waterpipe smoking was common among young college students (16-19). Cafes that facilitate smoking of waterpipes are becoming widespread especially in areas surrounding colleges and universities. These observations have recently led to the implementation of strict regulations by the Ministry of Health and the municipality of Amman. 
In this study, smoking habits also showed significant differences according to educational status, with a trend towards higher prevalence of smoking among those with intermediate educational level. Our findings are not in line with the overall trend of declining prevalence of smoking with increasing education in the USA, in which smoking prevalence was found to be high among adults who had earned a general educational development diploma (43.2\%) and those with 9-11 years of education (32.6\%) (20). In the USA, Finland and Australia smoking rates correlated inversely with educational level (20-22).

Initially we did not find a significant association between income status and smoking prevalence in Jordan. However, we found that males with lower income were more likely to smoke than those with higher incomes. This accords with has been reported in the USA and Finland, where a higher prevalence of smoking was associated with lower income $(20,21)$.
With regards to marital status, smoking prevalence among single and married individuals was very similar (36.5\% versus $33.0 \%$ respectively), whether analysing males, females or both sexes. This is in contrast to a Swedish study showing a higher prevalence of smoking among single than married people (23).

It is important to note that, consistent with other self-reporting interview methods, individuals may be reluctant to explicitly state their smoking practices and may rather provide answers that are socially acceptable. However, a significant strength of our study was the involvement of a representative sample of the Jordanian population.

\section{Conclusion and Recommendations}

Reducing the prevalence of smoking in Jordan must be set as a priority.
Reducing the prevalence of smoking can be approached through education, particularly among the youth. In addition, creation of smoking cessation programmes and primary prevention programmes that promote nonsmoking can be useful. Official action through activating current laws and regulations and imposing new ones is of vital importance.

\section{Acknowledgements}

Funding: This work was supported by the Arab Fund for Economic and Social Development (AFESD). The KAP survey was implemented by King Hussein Institute for Biotechnology and Cancer (KHIBC) under the National Life Science Research and Biotechnology Promotion (LSR/BTP) Initiative in Jordan.

Competing interests: None declared

\section{References}

1. Controlling the smoking epidemic. Geneva: World Health Organization; 1979 (Technical Report Series No 636).

2. Jacobs DR Jr, Adachi H, Mulder I, Kromhout D, Menotti A, Nissinen A, et al. Cigarette smoking and mortality risk: twentyfive-year follow-up of the Seven Countries Study. Arch Intern Med. 1999 Apr 12;159(7):733-40. PMID:10218754

3. Martinet $Y$, Wirth N. Smoking-related diseases. In: Palange $P$, Simonds AK, editors. ERS handbook of respiratory medicine. Lausanne: European Respiratory Society; 2013.

4. Guidelines for controlling and monitoring the tobacco epidemic. Geneva: World Health Organization; 1998.

5. Information and research for better health. Issue 1. July 2013. Amman, Jordan: Ministry of Health; 2013 (in Arabic) (http:// www.moh.gov.jo/AR/Documents/rep2012.pdf, accessed 12 May 2014).

6. Jordan Cancer Registry. Cancer incidence in Jordan. Amman, Jordan: Ministry of Health; 2009.

7. Mackay J, Eriksen M, editors. The tobacco atlas. Geneva: World Health Organization; 1985.

8. Bassiony MM. Smoking in Saudi Arabia. Saudi Med J. 2009 Jul;30(7):876-81. PMID:19617999

9. Report on the global tobacco epidemic, 2008: the MPOWER package. Geneva: World Health Organization; 2008.

10. Guindon EG, Boisclair D. Past, current and future trends in tobacco use. Washington (DC): The International Bank for Reconstruction and Development / The World Bank; 2003.

11. Kish L. Survey sampling. New York: John Wiley and Sons, Inc.; 1965.
12. Ahram M, et al. Public perception of biobanking in Jordan. Biopreserv Biobank. 2012;10(4):361-5.

13. Smoking and tobacco use: trends in current cigarette smoking among high school students and adults, United States, 1965-2010. Atlanta (GA): Centers for Disease Control and Prevention; 2011 (http://www.cdc.gov/tobacco/data_statistics/ tables/trends/cig_smoking/, accessed 12 May 2014).

14. Women and the tobacco epidemic: challenges for the 21st century. Geneva: World Health Organization; 2011.

15. Peto R, Lopez AD, Boreham Ji, Thun M, Heath C Jr, editors. Mortality from smoking in developed countries 1950-2000: indirect estimates from national vital statistics. New York (NY): Oxford University Press; 1994.

16. Azab M, Khabour OF, Alkaraki AK, Eissenberg T, Alzoubi KH, Primack BA. Water pipe tobacco smoking among university students in Jordan. Nicotine Tob Res. 2010 Jun;12(6):606-12. PMID:20418383

17. Chaaya M, El-Roueiheb Z, Chemaitelly H, Azar G, Nasr J, AlSahab B. Argileh smoking among university students: a new tobacco epidemic. Nicotine Tob Res. 2004 Jun;6(3):457-63. PMID:15203779

18. Khabour OF, Alzoubi KH, Eissenberg T, Mehrotra P, Azab M, Carroll MV, et al. Waterpipe tobacco and cigarette smoking among university students in Jordan. Int J Tuberc Lung Dis. 2012 Jul;16(7):986-92. PMID:22525279

19. Mzayek F, Khader Y, Eissenberg T, Al Ali R, Ward KD, Maziak $W$. Patterns of water-pipe and cigarette smoking initiation in schoolchildren: Irbid longitudinal smoking study. Nicotine Tob Res. 2012 Apr;14(4):448-54. PMID:22140149 
20. Tobacco use among adults: United States, 2005. MMWR Morb Mortal Wkly Rep. 2006 Oct 27;55(42):1145-8. (http:// www.cdc.gov $/ \mathrm{mmwr} / \mathrm{preview} / \mathrm{mmwrhtml} / \mathrm{mm} 5542 \mathrm{al} . \mathrm{htm}$, accessed 14 May 2014).

21. Laaksonen M, Rahkonen O, Karvonen S, Lahelma E. Socioeconomic status and smoking: analysing inequalities with multiple indicators. Eur J Public Health. 2005 Jun;15(3):262-9. PMID:15755781
22. Australian social trends 2000. Canberra: Australian Bureau of Statistics; 2000 (http://www.ausstats.abs.gov.au/ausstats/ subscriber.nsf/0/0061403922BF6F55CA2569110080BA2C/\$F ile/41020_2000.pdf, accessed 12 May 2014).

23. Lindström M. Social capital, economic conditions, marital status and daily smoking: a population-based study. Public Health. 2010 Feb;124(2):71-7. PMID:20181369 